Red de Investigadores Educativos Chihuahua A.C. Chihuahua, México
ISSN: 2007-4336

ISSN-e: 2448-8550

http://www.rediech.org/ojs/2017/index.php/ie rie rediech/index

\author{
Míriam Piani Mailhos
}

2019

\title{
Huellas biográficas de experiencias educativas en la conformación de subjetividades políticas
}

IE Revista de Investigación Educativa de la REDIECH, 10(18), pp. 207-224.

http://dx.doi.org/10.33010/ie_rie_rediech.v10i18.602

\section{(c) (1) (9)}

Esta obra está bajo licencia internacional

Creative Commons Reconocimiento-NoComercial 4.0.

CC BY-NC 4.0 


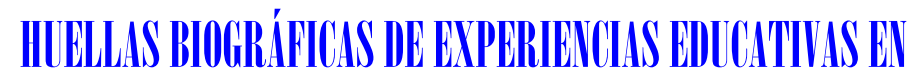

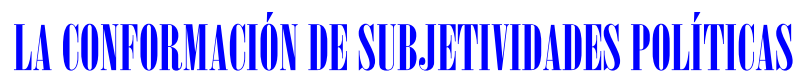

\author{
BIOGRIPIIICHL TRLICES OF EDICITIOILL EXPERIEICES II

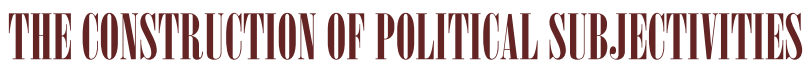

PIANI MAILHOS Míriam

\begin{abstract}
Regepción: enero 14 de 2019 | Aprobado para publicación: abril 2 de 2019
DOI: https://dx.doi.org/10.33010/ie_rie_rediech.v10il 8.602
\end{abstract}

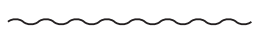

\section{Resumen}

Esta investigación ${ }^{1}$ está situada en instituciones de Bariloche. ${ }^{2}$ Partiendo de la relación que existe entre el proyecto colonizador occidental y los procesos educativos, a partir de una perspectiva decolonial en diálogo con categorías teóricas críticas, se indaga en las experiencias educativas de docentes, estudiantes y graduados, recuperando huellas de colonizaciones -maneras de ser-estar hacer en el mundo y de conocer-; y pistas como rupturas en la construcción de subjetividades políticas. A partir de una indagación cualitativa, se pudo comprender que los procesos colonizadores y decoloniales se dan en simultáneo, y si bien, las experiencias que rompen la hegemonía, habitan tanto en ámbitos formales como no formales, siendo más frecuentes en este último. Señalamos que en todas ellas el sujeto es afectado en tránsitos hermenéuticos corporales, o bien, queda impactado estéticamente. Algunas construcciones de enseñanzas que se visibilizan como potencial de ruptura, no tienen el impacto que se busca. En cuanto a las normativas que regulan los

${ }^{1}$ En el marco de la tesis doctoral "Desde la formación de formadores hacia la transformación socioeducativa: rescate de huellas biográficas de experiencias educativas en la construcción de las subjetividades" (2014-2017).

2 Patagonia, Argentina.

Míriam Mónica Piani Mailhos. Profesora adjunta e investigadora de la Universidad Nacional del Comahue, Argentina. Es doctora en educación por la UNC-Argentina y magíster en evaluación educacional por la Universidad de Ciencias de la Educación de Playa Ancha-Chile. Miembro del comité académico de la revista EFEI del Centro Regional Bariloche de la Universidad Nacional del Comahue. Coordinación de cursos de posgrado y de formación docente continua. Es autora de artículos y libros en relación a la educación, arte, prácticas pedagógicas y evaluación. Participante en proyectos de extensión relacionados con el fracaso escolar y la construcción coinstitucional de saberes. Correo electrónico: mpiani4@yahoo.com.ar. ID: https://orcid.org/0000-0001-9509-2312. 
procesos pedagógicos, en algunos casos facilitan emancipaciones y en otros siguen reproduciendo colonizaciones.

Palabras clave: FORMACIÓN DOCENTE, EXPERIENCIA EDUCATIVA,
DECOLONIALIDAD, COLONIZACIÓN, SUBJETIVIDAD POLÍTICA.

\section{Abstract}

This research is located on higher education institutions of Bariloche. Starting from the complex relationship that exists between the western colonizing project and the educational processes, from a decolonial perspective in dialogue with critical theorical categories, it is inquired in the educational experiences of teachers, students and graduates; recovering traces of colonization, in terms of ways of being-living-doing in the world and knowing; and clues as breakdowns in the construction of political subjectivities. Based on a qualitative inquiry, it can be understood that colonization and decolonization processes are given simultaneously, an although, the experiences that breakdown the hegemony, are present in formal and informal areas, being more frequent in the latter. We point out that in all of them the subject is affected in the corporal hermeneutical transits or remained aesthetically affected. Some constructions teachings that are visible as potential breakdowns, do not have the impact that we are looking for. Concerning the pedagogical processes regulations policies, in some cases they facilitate emancipations, and in other cases, colonizations are reproducing.

Keywords: TEACHER TRAINING, DECOLONIALITY, COLONIZATION, EDUCATIONAL EXPERIENCE, POLITICAL SUBJECTIVITY.

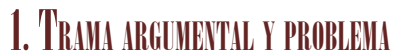

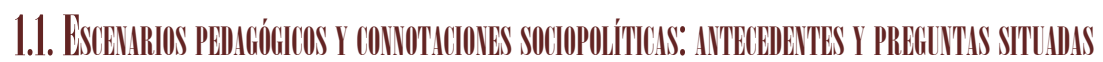

A 10

largo de la historia encontramos relatos que visibilizan luchas de poderes configurando un dominio de algunos sujetos sobre otros. Esta escena, además de ser territorial, se traduce en la imposición de maneras de ser-estar y hacer en el mundo y de formas de conocer, que en Santos Souza (2010) son ontologías y epistemologías que asumen el contenido y la lógica del proyecto colonizador occidental-moderno, según análisis decoloniales. Este modelo es el que se ha impuesto como sistema de dominación.

Esta imposición, entre otras cosas, implica la expropiación del tiempo (Berardi, 2007; Vega Cantor, 2012), desde donde se teje toda una dinámica de vida. Ese tiempo que mientras se "gana", se pierde como posibilidad no alienante y vital. Esta es una lógica que siempre encuentra otra cosa más que hacer para ganar tiempo, y

208 en el mismo hecho de ganarlo el tiempo vital se escurre entre los dedos. Traemos 
la concepción del tiempo como uno de los tantos matices, pues asumimos, luego de nuestro trabajo, que en ello reside una de las claves para destramar el sistema imperante este mundo mundial.

Son investigadores y teóricos como Foucault (1975), Freire (1990), Giroux (1990), McLaren (1995) Apple (1987), Bourdieu y Passeron (1996), entre otros, quienes en el campo de la educación, y desde otros campos vinculantes, abren los primeros horizontes para pensar, desnaturalizar y comprender los escenarios educativos en relación a estos procesos de imposición; es decir, para leer la pedagogía en clave sociopolítica, alertando sobre prácticas de reproducción social hegemónica en el creciente contexto de la globalización política, económica y cultural.

Desde esta perspectiva, los procesos educativos no son ingenuos; incluso aquellos que se desarrollan en espacios no formalizados que hacen a la socialización, como la familia, la religión, los clubes, entre otros (Guattari y Rolnick, 2006). Estos están ligados a encarnaciones y a la construcción de proyectos sociales y políticos a través de dispositivos y prácticas de las que devienen los escenarios para la experiencia, donde se van construyendo las subjetividades, que también son políticas.

Es en esta línea paradigmática-argumental en la que se inscribe esta tesis, diferenciándonos de los trabajos en investigación educativa entre cuyos autores se encuentran Dunkin y Biddle (1974), Bennet y Jordan (1975), Stodosky (1991), que desarrollan sus conceptualizaciones a partir de concebir a la práctica pedagógica como una práctica de racionalidad técnica.

Entre los antecedentes que pudimos recuperar, tenemos los de investigadores de las instituciones en que desarrollamos la indagación, que ya habían advertido en sus conclusiones que era escaso el impacto que tenía la formación superior situada en las prácticas de docentes nóveles egresados de dichos centros educativos, y que estos maestros, maestras y profesores desempeñaban su rol docente como lo habían vivido en sus procesos de escolarización; es decir, desde sus biografías escolares (Alliaud, 2004).

Desde nuestra perspectiva, y considerada la educación como posibilidad de emancipación y transformación social, ${ }^{3}$ especulamos que el problema no se explica desde lo disciplinar únicamente, sino que las prácticas reproductivas siguen reponiendo el proyecto socializador hegemónico al homogeneizar la enseñanza, saberes y lógicas, construyendo un dispositivos que enseña; como aprendizaje adicional (Jackson, 1988), una forma de ser-estar-hacer en el mundo y de construir conocimiento desde el "uni-verso" en oposición al "pluri-verso" (Botero Gómez, 2015) y a la diversidad cultural no subsumida.

Esta reproducción que circula en el sistema educativo en general, y en particular en nuestra región patagónica que alberga a sujetos de distintos orígenes sociales, étnicos, culturales e históricos, es una forma de despojo que niega la alteridad provocando, en la práctica continua, profunda y preobjetiva, epistemicido y statu quo social. Es colonización epistémica y ontológica para la colonización política (Mingolo, 2003) a partir, entre otras cosas, de la educación que reproduce.

Esta visibilización constituyó uno de los dos ejes de la tesis a partir del cual surgió la siguiente pregunta: ¿cómo, en forma situada, se continúa reproduciendo

\footnotetext{
${ }^{3}$ Y no solo para el trabajo.
} 
la colonización de mentalidades en las experiencias educativas, como diría Souza Santos y Meneses (2014), hechas cuerpos (que completo ${ }^{4}$ desde una postura monista en la que me posiciono)?

No obstante, estas reproducciones en las prácticas de la enseñanza observamos desde trayectorias propias y compartidas en intercambios con otros sujetos, que además existen otro tipo de experiencias educativas, que significaron un antes y un después en nuestras vidas. Experiencias que dejaron huellas de rupturas en las continuidades reproductivas. Escenarios que desafiaron la homogeneización, y con ello, la inequidad que esto implica en término de legitimaciones y posicionamientos sociales. Estos dispositivos y prácticas distintivos, en donde la experiencia educativa se desarrolló, plantearon espacios concretos y distintos en la construcción de subjetividades políticas con un impacto real. Aparentemente estos escenarios compartían la valoración de la alteridad y una nueva forma de constituirse en el desarrollo de la enseñanza.

Recuperando lo explicitado fue que nos preguntamos, si son "estas otras cosas" las que podrían estar hablando de transformaciones socioeducativas en la microestructura. Es decir, nos preguntamos: ¿cómo, en forma situada, se producen los procesos específicos que construyen puentes emancipadores en los escenarios pedagógicos? Este fue el segundo eje orientador que tuvo la tesis.

\subsection{De horizontes semínticicos a objetivos concreteos}

A lo largo del proceso de investigación, buscamos huellas en las experiencias educativas formales y no formales de docentes, estudiantes y graduados que al analizarlas nos fueron dando manifestaciones de colonizaciones situadas y pistas que interrumpían ese proceso reproductivo colonizador.

Considerando con Scott (1999), por un lado, que la experiencia se trama discursivamente, y que en esas tramas se encuentran implícitas las operaciones ideológicas que subyacen, y recuperando, por otro lado, lo que Grosfoguel (2006) expone sobre el hecho que las colonizaciones se han dado en las experiencias, comprendimos la importancia de acudir a los relatos de las mismas. Para ello fue necesario acceder tanto al discurso de sujetos pertenecientes a grupos sociales dominantes como de sujetos de grupos sociales que sufrieron invisibilizaciones y además, observar lo que nos decían sus corporalidades.

Nuestro objetivo era, a partir de las narraciones encarnadas ${ }^{5}$ develar sentidos y significados implicados en las tramas de interrelación/poder pedagógica, dentro del contexto en que esas experiencias se produjeron, con un sujeto involucrado en el mismo juego que "cuenta"; un sujeto que describe con voz propia, que es también, la voz del grupo social al que pertenece, su historia.

${ }^{4}$ En el escrito aparecen redacciones en primera persona del singular; esto es una decisión intencional, que asumo bajo mi propia responsabilidad, en relación a un desvío conceptual que realizo en función a trayectoria particulares que fui realizando.

$210{ }^{5}$ Cuando uno, una, narra, narra más que palabras, narra miradas, narra tonos musculares traducidos en posturas y gestos. 
Esta circulación nos permitió una praxis investigativa comprometida socialmente, generando en $\mathrm{mi}^{6} \mathrm{y}$ en el entrevistado/a-narrador/a, aprendizajes vitales y algunas interrupciones a nuestras propias lógicas occidentales "universalizadas" sin haberlo buscado como objetivo, lo cual, en sí mismo generó una nueva forma de entender otra manera de estar-ser-hacer juntos en el mundo, construyendo en este intersticio, otro mundo posible (Botero Gómez, 2015), conservando una distancia óptima a partir de nuestra vigilancia epistemológica, la autoobservación y los procesos de reflexividad.

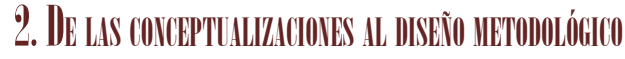 \\ 2.1. De qué hablatimos cillindo hathlimlos}

Etimológicamente la palabra huella proviene del latín, del verbo hollar que puede traducirse como "pisar dejando una marca en el suelo", con estas nos encontramos en nuestra ruta, recuperando las narrativas. Marcas en el "suelo" como metáfora de aquello que sucede y que les sucedió en los relatos de experiencias educativas en distintos ámbitos a los sujetos. Aquellas que se materializaron en el lenguaje y que se "hicieron" cuerpos subjetivos/sociales, y con-figuraron relatos hechos biografias en una sucesión narrativa de experiencias.

En relación a esto de la experiencia, Mohanty (1991), plantea que no hay una experiencia, sino que hay capas o niveles de experiencias. Fue en relación a esta idea que recuperamos desde dos enfoques teóricos totalmente distintos su conceptualización. Desde Gadamer (1977), la experiencia es un acontecer de sentido, en cuyo horizonte del aquí y el ahora, se recupera en el presente, el pasado y el futuro. Este proceso hermenéutico dialéctico lleva en sí mismo la potencia de la comprensión, $\mathrm{y}$ en todo caso, el movimiento reflexivo que involucra la conceptualización de lo vivido, se hace a posteriori. Mientras que para Dewey (1944), la experiencia es el resultado, signo y recompensa de las interacciones que hace el individuo, y distingue el experimentar de a la experiencia. En este sentido, la experiencia es proceso y no solo acto, como lo es el experimentar, que vendrían siendo parte del proceso. Este teórico diferencia, además, la experiencia cotidiana de la experiencia estética que, si bien ambas poseen relatos emocionales, la última está ligada a la percepción y al gozo. No obstante, la clara diferencia entre ambas perspectivas teóricas, estas comparten la caracterización monista desde donde la experiencia se trama en forma simultánea como relato emocional, cognitivo-perceptivo; y en donde las narrativas, visibilizan las gestiones ideológicas subyacente. Estos procesos de incorporaciones, al decir de Bourdieu, tejen, de acuerdo a los análisis de Duch et al. (2008), corporeidades que implican síntesis sociales/singulares, es decir, tramas en donde los relatos sociales y los relatos individuales ${ }^{7}$ se materializan en corporalidades, pensamientos hechos carne y carne hecha pensamientos. En relación a esto, y recuperando, además, lo que plantea Walsh (2015) sobre el hecho que donde hay enseñanzas y aprendizajes, hay reproducciones y/o transformación sociales; los escenarios educativos, donde

${ }^{6}$ Incluyo la primera persona del singular, pues estas experiencias fueron únicas y solo yo estuve involucrada.

${ }^{7}$ Como historicidad del sujeto. 
se viven las experiencias no son ingenuos, como advertimos. En estos espacios se desarrollan "procesos ontológicos que se construyen en el actuar con las cosas tal como se las comprende, que a su vez genera marco para esa misma comprensión desde donde surgen los sentidos y los significados" (Alvarado et al., 2008, p. 7). De esta manera, se va incorporando habitus, es decir, estructura estructurante, duradera, que implican creencias, competencias, valores, etcétera. Desde esta perspectiva, entonces, los escenarios pedagógicos proponen espacios para la construcción de subjetividades políticas, es decir, "posibilidad de aparecer en el mundo por medio de las palabras y actos que llevan a distinguirnos como un quién plural" (Botero Gómez, Cardona y Loiza, 2007, p. 3). En este sentido, los escenarios pedagógicos son performativos, ya que plantean composiciones donde el poder (colonizador) encarna procesos de culturalización hegemónica, según los análisis de Quijano. Esta hegemonía, no solo se sostiene desde un sistema de dominación de clase y de género, sino que plantea, fundamentalmente, procesos en relación al ser, al saber y al poder; poder que impone y poder que se "roba" para legitimar el ser y el saber, es decir, ontología y epistemología dominante. En un giro, y como forma de resistencia semiótica para pensar la imposición hegemónica (Quijano, 1988; Souza Santos, 2010; Escobar, 2003), emerge el pensamiento plural, que según Prada Alcoreza implica un pensamiento complejo que se caracteriza por recuperar la multiperspectiva en la construcción del objeto como epistemología pluralista, a nuestro entender transdisciplina cognitiva epistémica, pensamiento que además construye realidad desde una ecología de saberes (Souza Santos et al., 2014), en la interacción continua y dinámica, interconocimiento sostenido en una ontología relacional, ontologías plurales en Escobar (2016) y Zibechi (2015). Estas premisas sintetizan una pedagogía decolonial, que entre otras características "hace despertar", y que, según Fanon (1973), volverá a humanizar a la humanidad. Para Walsh, esta se basa en didácticas ancestrales y en Souza Santos, se sostiene desde teorías de retaguardia; para hacer despertar, alentar la autoagencia y acción, facilitar la formación de subjetividad y autorreflexión y fomentar y revitalizar racionales políticas éticas otras que se distancian de la razón moderna occidental (Walsh, 2013). El gráfico que compartimos en la figura 1 sintetiza el movimiento desde el que parte nuestra composición semántica.

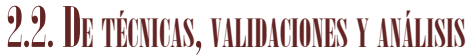

$\mathrm{Al}$ andar por las huellas de las experiencias, además de recurrir a otras fuentes secundarias para triangular los datos que íbamos construyendo, reconstruimos sentidos y significados que nos permitieron comprender algunos procesos que se iban desplegando a partir de los análisis. Metodológicamente recuperamos narraciones de experiencias educativas en entrevistas en profundidad y observación de clases, y a partir de allí penetramos desde un enfoque sociopolítico; concretamente el decolonial con aportes de trabajos críticos; a la información recogida, a fin de destramar los relatos.

El muestreo teórico (Glaser y Strauss, 1967), fue nuestra decisión para incorporar a los sujetos y los espacios para observar. A medida que transcurría la investigación, fuimos necesitando otros medios, algunos documentos, que nos permitieron

212 comprender más acabadamente las situaciones destramadas, y los tejidos implicados 
Fig. 1. Triada de afectación sincrónica visibilizada sobre el mar de fondo de las redes de poder.

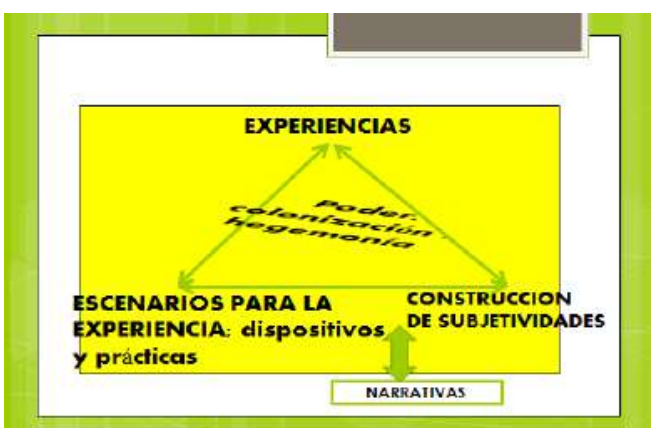

Fuente: Elaboración personal.

en las mismas. Los mismos fueron abordados en dos sentidos: como enunciaciones performativas y como fuentes secundarias de triangulación. Incluimos para tal fin los diseños curriculares de educación primaria y de educación especial, el diseño curricular de educación secundaria de biología, reglamentaciones sobre acreditaciones, y programas de cátedras de profesores entrevistados y clases observadas.

En coherencia con el diseño elaborado desde la tradición cualitativa, el análisis y elaboración de la información se llevó a cabo a partir de cuatro movimientos metodológicos: etiquetamiento, codificación, interpretación situada y dialéctica empiria, teoría según lo recuperado de Porta y Silva (2003), entre otros. Los procesos de validación siguieron los principios de los planteos de Taylor y Bogdan, (1987) por un lado, y de Moustaka (1994), a partir de procesos de autorreflexibilidad y de heterosupervisión, o validez intersubjetiva.

\subsubsection{De las unidades de andilisis a la constrincción de sentidos y significiadlos}

Los textos narrativos se traman en sentidos y significados, partiendo de esto, en el trabajo concreto con la información, las lecturas reiteradas y hermenéuticas fueron los puentes a partir de los cuales recuperamos la arquitectura de los discursos que se reproducían independientemente de los escenarios y matices experienciales relatados. Esto es, que aunque en las manifestaciones que configuraban las palabras, se dibujaban paisajes distintos, en las arquitecturas del entramado discursivo, se visibilizaban tejidos enunciativos similares. Como, por ejemplo, las situaciones de maltrato escolar, que se ponían en evidencia de maneras diversas y que, para distintos y distintas narradores, contenían el mismo relato de sentido y significado. En general cuando estas experiencias eran compartidas en las entrevistas en profundidad, el discurso iba acompañado por la elocuencia de los gestos que transformaba rostros y la ilocución de lo dicho, en todos los casos.

Fue así, que los relatos una y otra vez, con y en diferentes tintes, ritmos y manifestaciones, nos fueron llevando por caminos heurísticos. En esos párrafos, llenos de sentidos, pudimos encontrar actor/es, relaciones y elementos como fuerzas en tensión y en complementariedades, desde donde emergían aquellas huellas que estábamos 
buscando. Estos relatos se sucedían en formas diversas, a veces intempestivas. Trabajamos con información de:

- Relatos de las experiencias de enseñanzas y aprendizajes en los distintos ámbitos educativos.

- Dinámicas, contenidos y estéticas de situaciones de enseñanzas.

- Documentos, escritos pedagógicos e institucionales, que destramamos a partir del análisis.

- Eventos, organizaciones en los centros educativos estudiados, de los cuales fui parte como observadora participante, que nos sirvieron para rescatar los contextos institucionales en los que transcurrían las experiencias educativas.

\section{Conculsiones}

\subsection{Volviendo sobre nuestros passos: tomas de conciencia y apprendizijes}

En los comienzos de esta tesis conceptualizamos a la formación de formadores desde una perspectiva cualitativa pedagógica, planificábamos comenzar con nuestro muestreo teórico desde ese margen. Con el tiempo de andar la investigación, y sobre todo, en el momento que fuimos "al campo", nos dimos cuenta que este enfoque conceptual, si bien nos aportaba conocimiento en relación al sentido y significado de nuestra situación-objeto de estudio, nos quedábamos sin una estructura concreta a partir de la cual obtener con sistematicidad los relatos de experiencias y de las prácticas, por lo que necesitamos, además de esta conceptualización, poder realizar una cartografía del territorio y determinar concretamente una frontera. Ese fue el segundo punto de partida, y con esto, vino la selección de 4 de los profesorados ${ }^{8}$ existentes en la ciudad. Dentro de estos, nos movimos para el muestreo, tanto en el campo de la práctica, como en el de la formación específica, pasando por materias de la formación general, ancladas en lo pedagógico. ${ }^{9}$

En nuestras hipótesis suponíamos que las rupturas; al decir de Hall: aquellas "donde las viejas líneas de pensamiento son desarticuladas, las constelaciones más antiguas son desplazadas y los elementos -viejos y nuevos- son reagrupados en torno a un esquema distinto de premisas y de temas" (2006, p. 233); que sucedían en la trama de reproducción hegemónica, estaban dadas en relación a experiencias educativas no formales, incluso, estas hipótesis las sosteníamos en contra de nuestras propias narrativas autobiográficas. No obstante, descubrimos que también aparecieron esas situaciones, al igual que en nuestros relatos, en las narrativas de experiencias educativas formales, voces que nos relataban transformaciones y rupturas en esos tejidos reproductivos escolarizados, ya sea por la forma de enseñar/vincularse de

${ }^{8}$ Profesorado de biología, educación especial con mención en discapacidad intelectual, educación primaria y educación física, en un total de 9 aproximadamente que posee Bariloche. Los profesorados elegidos contaban con datos previos de trabajos e investigaciones que nos aportaban información con respecto a lo que estábamos investigando.

${ }^{9}$ Retomando la categorización que el Infod (Instituto Nacional de Formación Docente) en los 214 lineamientos curriculares de sugerencia para diseñar planes de estudio para la Argentina durante el periodo 2007-2015. 
docentes o por las composiciones de los escenarios pedagógicos, que se diferenciaban claramente de los de reproducción. Otra de las cuestiones que nos sorprendió, y de la que aprendimos, fue el rol de lo temporal en la organización estructural para las experiencias educativas, que según nuestros análisis vuelve a encarnar un tiempo ajeno a procesos vitales para las enseñanzas y los aprendizajes, "domesticando cuerpos" y silenciado otras cualidades de lo temporal para ser-estar-hacer y conocer en el mundo. Tiempos impuestos y segmentados, que en su correr incorporan esquemas perceptivos, a los que, estudiantes y docentes nos tenemos que adaptar, condicionando y reproduciendo la monocultura de la organización y eficiencia del tiempo, a través relatos que se escriben en las corporeidades.

Descubrimos que a la mayoría de las experiencias narradas se les puede intentar poner un nombre, etiquetar, como plantea Dewey (1944), con una cualidad que las distingue. Además, pudimos apreciar, desde las narrativas de estas experiencias educativas, que, de hecho, conviven los conceptos de Dewey (1944) y de Gadamer (1977), ya que plantean distintos grados de afectaciones del sujeto, y eso se visibiliza, además que en el discurso, en las corporalidades en el momento que están narrando. A las experiencias donde el sujeto se sumerge en sí mismo, e incluso parece volverlas a vivenciarlas emocionalmente por conflictos, fracasos, frustraciones que se dan en situaciones educativas, las denominamos experiencias hermenéuticas ontológicas de enseñanza y de aprendizaje: son experiencias de subsuelos, hermenéuticas del sujeto, a las que este llega por situaciones límites que vienen desde el afuera con cierta relación de los procesos subjetivos por los que está atravesando. Según se destrama desde las narrativas, en ellas quedan desarticulados todos los esquemas que tenía como herramientas para la enseñanza o se desarticulan los esquemas emocionales que sostenían sus trayectorias de aprendizaje. La, el entrevistado se hace consciente de esto, sintiendo que lo que tiene no le alcanza para proponer la enseñanza o que hubo un quiebre en su trayectoria escolar, en el caso de relatos de épocas de estudiante. En este último rol, estas vivencias, aparecen por situaciones traumáticas que vivieron, quedando expuestos especialmente por personas que obran desde el lugar de la autoridad.

\subsection{De las ciategorias emergentes}

Como ya lo expresamos anteriormente, fuimos analizando, interpretando y dialogando con la teoría, de este proceso construimos las siguientes categorías:

\subsubsection{Inmilliticiones escoliares}

Son situaciones de maltrato que se repiten en exposiciones que docentes hacen de estudiantes. No hablamos de bullying, pues tomamos el sentido y significado del sujeto expuesto, un maltrato que se traduce en su propia emoción como "humillación".

Tal es el caso de Rosario, ${ }^{10}$ estudiante perteneciente a una comunidad rural patagónica, quien además de otros relatos nos contaba: "En la primaria pasé algo muy feo, me hicieron pasar al frente, creo que era con el tema de las capitales de las provincias, allí me trabé, no supe que decir, y el maestro con todos los chicos se

\footnotetext{
${ }^{10}$ Reemplazamos en todos los casos los nombres para evitar una nueva exposición.
} 
empezaron a reír. De allí me costó mucho volver a hablar así delante de todos, es como que me expuse mucho y se rieron de mí. Me equivoqué y en vez ayudarme se largó a reír el maestro, eso me molestó y me dolía [cambia el tono de voz se hace más firme]. Era como que me costaba después expresarme..." (estudiante del Profesorado de Educación Especial).

0 en el testimonio de Marcos (estudiante del Profesorado de Educación Física): "Una maestra de la secundaria, de 3ro., no me acuerdo que estábamos haciendo en esa clase que salió el tema y la maestra me expuso en medio de la clase diciéndome que yo no sabía nada, desde esa vez dejé de socializar porque yo era muy extrovertido, y desde allí fui mucho más para adentro, desde allí me cuesta dar orales, exponerme. Con mis compañeros empecé a hablar con los que me sentaba solamente, era con ellos con los que más socializaba, desde allí no le presté tanto a lo social, las lecciones orales me costaron".

Estas narrativas, visibilizan en palabras, el dolor de las experiencias de sí que tuvieron estos estudiantes en clases situadas, uno en el nivel primario y otro en el nivel secundario. Estos dos párrafos que elegí, son los más representativos entre muchas otras situaciones que reflejan el mismo relato con otras manifestaciones, y que no necesariamente tienen que ver con un contexto sociocultural determinado, si bien, se dan en estudiantes que pertenecen a grupos minoritarios, principalmente, en nuestro muestreo teórico, no obstante, también encontramos este tipo de experiencias en estudiantes de clases medias urbanas, cuya característica era que no se acomodaban a la norma y además, daban sus argumentos. Para los y las estudiantes del primer grupo, esto mismo los y las llevó a elegir la profesión con el objetivo de "vengarse" o "volver y hacer las cosas de otra manera para que no sufrieran inocentes", según sus propias palabras. Para los y las del segundo grupo, significó desafíos que superaron y reconvirtieron en su práctica pedagógica con nuevas formas de hacer y ser-estar en la enseñanza.

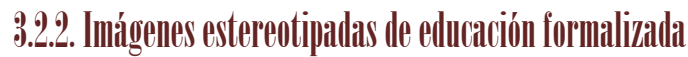

Son estéticas que se repiten independientemente del contexto sociocultural que se trate: docentes en posesión de la palabra la mayoría del tiempo, bancos en hileras, rituales de trabajos pedagógicos que varían en temática mas no en su forma metodológica, escenarios que dejan afuera la palabra/experiencia/saberes de los y las estudiantes en temas que pueden prestarse para la diversidad argumentativa. Con esto, consideramos, se sigue reforzando la lógica de la monocultura occidental dualista, epistemología universal, a través de la incorporación del habitus que actúa como estructura estructurante; cuerpos "mágicamente calladitos y tranquilitos" mientras que "pensabas en otra cosa" (recuperado del diálogo con Prof. del CRUB ${ }^{12}$ ); cuerpos y mentes disociadas, en continuidad al dualismo cartesiano. Pedagogías sin cuerpos, y sin embargo, que hacen modo operandi en los cuerpos para seguir reproduciendo las premisas y temas del sistema colonizador hegemónico, que son las neocolonizaciones. Corporalidades quietas y calladas, en el control del cuerpo sedentario y en el

\footnotetext{
216

${ }^{11}$ Dichos de los y las entrevistadas.

${ }^{12}$ Centro Regional Universitario Bariloche.
} 
discurso monopolizado, a partir de las cuales observamos que se van construyendo subjetividades en el entretejido, un aprendizaje adicional de sentidos y significados sociales de una ontología y epistemología dominante, que es ontología no relacional en enseñanzas y aprendizajes descontextualizados.

A continuación transcribo un párrafo perteneciente a una observación de clase y dos segmentos de entrevistas, como testigos de la categoría: "El profesor al llegar se 'instala' en el frente [...] Él en el frente, los estudiantes en hileras uno detrás de otro, la típica aula... Hace mucho calor en el aula, que es pequeña y contiene a mucho/as estudiantes. Sacan una fotocopia que el docente indica y comienzan a leer."13

"Cuando dictas los chicos se quedan mágicamente tranquilos y calladitos, eso me parece que está ligado en todos, a esas clases de las que hemos quedado impregnados no solo de la Universidad sino también en la escuela secundaria", nos contaba Alejandro (profesor y graduado de la UNco), o Ricardo (estudiante de la carrera de Educación Física de la Universidad Nacional del Comahue), quien desde su experiencia en la escuela secundaria recuperaba esta escena en la entrevista: "Teníamos también una profesora que hablaba toda la clase, no te dejaba hablar, vos mientras hablaba te ponías a pensar en el recreo o en otra cosa. Y en el examen nos mataba, yo me llevé dos años esa materia". En estas imágenes estereotipadas de educación institucionalizada escolar ${ }^{14}$ reconstruidas desde las narrativas, hay una evidente ausencia, y es la de los sujetos que aprenden, invisibilizados en modelos pedagógicos que no incluyen sus lógicas, por lo tanto, como ya dijimos, la de sus contextos socioculturales.

\subsubsection{Tiempos escolitres, tiempos enitjentidlos}

Son aquellos tiempos que se organizan más allá de las caracterizaciones del lugar y de las necesidades temporales para las enseñanzas y los aprendizajes. Son tiempos compartimentados, donde no se logran aprendizajes profundos, encarnando, no solo una forma de estudiar para aprobar, sino y además, lógicas de enajenación a los propios ritmos y tiempos cognitivos. Son tiempos emparentados con el modelo de la producción y el trabajo acorde a la monocultura de productiva capitalista (Moreira y Gois, 2007), donde a periodos organizados corresponden recreos, que incluso se organizan con juegos, en el caso de las escuelas en nuestra región. Además de esta ejemplificación, que visibiliza la esquematización del tiempo vital; los planes de estudio; con gran porcentaje de materias cuatrimestrales, que desde la argumentación de expertas "no alcanza el tiempo", constituyen otra visibilización, y se nota la diferencia en el aprendizaje si se compara con materias anuales"; algunas de las reglamentaciones de acreditación, son otra manifestación de lo mismo, que exigen a los y las estudiantes un aprendizaje en tiempos récords, como por ejemplo, la reglamentación para seminarios; por la cual los y las estudiantes de grado no tienen la opción de turnos de exámenes. En este sentido la organización del horario

${ }^{13}$ Fragmento obtenido y recuperado en una clase de escuela secundaria de S.C. de Bariloche.

${ }^{14}$ Sustituimos educación formal por educación institucionalizada escolar, ya que con Sirvent et al. (2006), suponemos que no existen las fronteras estrictas en los procesos educativos. En todo proceso educativo se "mezclan" componentes formales, informales y no formales. 
escolar, también, aporta a estas matrices que obran de escenarios/dispositivos donde se constituye la experiencia de sí.

\subsubsection{Construcciones metodológicias decoloniales}

Las definimos como estos actos singulares creativos que articulan (Edelteins, 2011) la epistemología del contenido, la lógica corporalizada del sujeto y el pluri-verso epistemológico que se hace texto en el contexto del aula, concibiendo y proponiendo nuevas y múltiples maneras de ser-estar-relacionarse en el micro-universo del aula que implican un pluri-verso ontológico. Estas son huellas de situaciones de enseñanza como aprendiz. En otro ejemplo recuperado (graduada del Profesorado de Biología, CRUB), nos cuenta: "Si la señorita de naturales... nos hacía experimentar con hojas con cosas naturales" y "fue la primera que trabajamos con diario, con la lectura de los diarios y armamos un mural y siempre me quedó como algo que me gustó... leer algo y compartir con otros...". En esta narración que recuperamos, la experiencia que propone "la señorita de naturales", vívida, variada desde una construcción del conocimiento con pluralismo epistemológico, en cuanto a que recupera lógicas de distintos campos de conocimiento. Una experiencia de enseñanza que abre a la pluriexploración del objeto de conocimiento, sin quizá llegar a un contenido construido como objeto desde varias lógicas.

Este tipo de experiencias educativas de enseñanza, según parece luego de triangulaciones que realizamos, se comienzan a tejer en tramas conflictivas, en que los y las docentes, visibilizan una falta de recursos frente a una situación que lo va desbordando: "Sufría cuando estaba con estos niños las 8 horas que tenía que estar allí, sufría los 40 minutos con cuadripléjicos con trabajo en el agua, sufría porque nada de lo que me habían enseñado podía bajar allí [...], porque los sistemas que se reprodujeron iban a lo rehabilitador, a lo médico, al éxito, sistemas reproductores que iban al valor del éxito sobre todas las cosas, pero en esos cuerpos lo menos que había era éxito, entonces empecé a improvisar, a hacer búsquedas, a hacer cosas que no eran habituales" (Carlos, profesor del CRUB). Situación vital, significativa y significada en sí misma, y que está signada por el conflicto.

La tensión/energía, que genera la misma práctica situada, obliga a buscar a los y las docentes, su descontracción. Desde su negatividad lógica, diría Gadamer (1977), su frustración, inicia un camino de búsqueda hacia nuevas formas de enseñar, en la que él mismo aprende con aquellos a quienes enseña. En esta experiencia confluyen el pasado, el presente y la construcción potencial del futuro en un solo acontecimiento educativo que es reversible, porque implica un afuera que se va construyendo desde una necesidad, y desde ese mismo afuera, que impacta profundamente, se construye, se re-crea, una forma nueva de praxis, que involucra la propia subjetividad como enseñante. Es la situación la que interpela, tensiona, y en la experiencia, el, la docente, observamos que, recorren caminos hermenéuticos que lo van llevando a una descolonización de la forma de ser-estar-hacer en la enseñanza. En él mismo, ella misma, todo aquello que en un momento estuvo cristalizado, que fue lo mismo que no le dio respuesta al obstáculo situado, aquí opera como posibilidad emancipadora,

218 según percibimos. 


\subsubsection{Rxperiencias educativas de fronteria}

Son aquellas que desafían las imágenes estereotipadas, en sus formatos y estéticas, no obstante este desafío, no alcanzan a quebrar las viejas líneas de pensamiento. La frontera como espacio límite entre lo que está adentro y lo que "se quedó" afuera de lo legitimado desde la matriz hegemónica. Estas prácticas pedagógicas abren, en sus formatos, el escenario de construcción de subjetividades al pluri-verso (Escobar, 2016).

Los relatos de los y las docentes visibilizan compromiso y entusiasmo con la tarea y un claro posicionamiento en cuanto a vitalizar los procesos de enseñanza, tal como lo evidencian estos relatos: “... además nosotros hacemos que ellos hagan conscientes estas rupturas, que describan lo que vivieron en la secundaria y lo que vivieron acá. Que los describan que puedan recuperar conceptos, a ellos les llama mucho la atención... en realidad es esta la forma en la que vamos y venimos en la biografía, además, los temas de la materia como ellos tienen experiencia solo se le va dando esta vuelta a la biografía" (Mónica, profesora del CRUB).

No obstante sus características, en un cruce de información que realizamos con los testimonios de los y las estudiantes, ninguno/a logró recordarlas, ni siquiera en el espacio de repregunta que hice, o sea, que parece que no existen como huellas en sus narrativas, según muestran estudios del desempeño de docentes nóveles.

Incluimos en esta categoría, además, otras experiencias que en sus aspectos exteriores parecen tener todos los elementos de las anteriores, no obstante en un análisis minucioso, observamos que en realidad, enmascaran, maquillan reproducciones. La docente, Susana (profesora del IFDC), está narrando los procesos de evaluación que se dan en su materia: “...Y no tienen que dar un oral, desde allí, de una manera creativa demostrarnos que comprendieron de eso [se refiere al tema que están dando], puede ser un sketch un móvil en directo, un cuento, un panel [...], se reenganchan con eso pero yo les digo no deja de ser un oral, ¿entienden?".

Visibilizamos en este párrafo testigo, el despliegue de la corporeidad, la inter-corporalidad, como rescate de historicidad y del cuerpo como espacialidad de situación, un yo soy, un yo puedo, a través de una consigna por donde pueden circular propuestas estudiantiles en cuanto al tema que enseñó la docente. No obstante esto, a través del discurso (uno de los componentes del dispositivo pedagógico en la construcción de subjetividades), notamos que se in-corpora el arbitrario cultural que contiene las formas homogeneizantes de desconocimiento de esa singularidad y que se materializan en estandarizaciones pedagógicas cuando les dice: "les digo no deja de ser un oral".

En esta expresión vuelve a encorsetar a los y las estudiantes en las estructuras estructurantes que se hacen cuerpo, en un habitus de esta monocultura no relacional que se reproduce, volviendo a los sostenes de la lógica colonizadora, según entendemos. En esta situación que traigo como relato: primero, se les da el espacio para que se expongan subjetivamente, para luego enjuiciarlos desde lugares estandarizados, el oral, con criterios resueltos exclusivamente por la decisión de los y las docentes. Esto, consideramos que tiene un agravante en sí mismo en relación al poder. 
La misma docente nos decía anteriormente: "Les tienen pánico al oral, ipero van a ser docente!, pero tengo una hipótesis que está muy pegada a la mirada de los demás, al juicio, entonces le da pánico". De estas palabras podemos deducir que para esta profesora, el ser docente implica estar "pegados" a la mirada de los demás, a lo que dicen los demás de nosotros. En función de la imagen que se compone profundizamos desde la perspectiva decolonial en el significado de la mirada, mirada que representa, al poder legitimado. La mirada que aprueba y o desaprueba y que implica otro de los escenarios para construcción subjetiva: otro, que con su voz en autoridad da significado al hecho.

\subsection{IPORTES Y REFLEVIOIES}

A partir de lo que hemos ido desarrollando, y a modo de hipótesis, planteamos varias aristas como aporte, como formas que cortan la continuidad de la reproducción:

- Las rupturas, parecería ser, no las hacen las pedagogías por sí mismas, sino los sujetos cuando se desnaturalizan a ellos mismos en función del discurso heredado de lo que son y lo que tienen qué hacer. A partir de esta ruptura con el sí mismo docente (forma de ser-estar-hacer en la educación), observamos que se lleva a cabo una especie de experiencia hermenéutica de sentidos y que estos acontecimientos, plantean un antes y un después. Luego, a partir de ensayar, probar caminos donde los y las docentes van recuperando elementos, intuiciones, estos componen nuevos escenarios pedagógicos, que resultan experiencias estéticas para muchos y muchas estudiantes, estas experiencias quedan como huellas en sus narrativas. Estas rupturas, son "desgarradoras", y se viven en términos prosaicos, como plantea Mandoki (1994).

- A partir de la empiria, ponemos en lugar de sospecha, el enunciado de Walsh (2015), tanto para pensar que las decolonizaciones se dan exclusivamente a través de didácticas ancestrales, como para el desaprender en términos de la eliminación de aprendizajes previos. Observamos que sucede -de acuerdo con lo que fuimos deduciendo en la elaboración de la información- que en este proceso, los viejos aprendizajes en sí mismos, obran de hitos referenciales para confrontar la situación vivida, aunque sea para corroborar que no tuvieron las herramientas para enfrentar el conflicto, o sea, como visibilización de un estado de falta más que como desaprendizaje.

- Si bien, percibimos que existen una serie de dispositivos pedagógicos que llevan a condicionar las formas perceptivas, como se fue desarrollando y visibilizado en las categorías enunciadas, parecería ser, según concluimos, que es el sujeto en proceso de formación docente, quien toma elementos puntuales de todos los que se ponen en escena, y es él mismo quien los plantea para su consideración. Quizás esto tenga que ver con la historia particular de cada uno/a, y del grupo social de pertenencia.

- Pudimos percatarnos que durante el proceso por el cual se dan las rupturas, hay autorreflexión constante en términos coloquiales no analíticos, según se visibiliza en los relatos. En relación a esto, observamos que no hay manifestación alguna 220 en las narrativas que sugiera que el sujeto "comprenda, in situ, y en términos 
conceptuales" su situación de "decolonización"15 en los términos planteados para los procesos de transformación (Freire, 2005), es decir, como hecho alfabetizador racional; sino que más bien, rescatamos, que se da una comprensión "no conceptualizada" y que podemos entenderla como comprensión "intuitiva" (Gadamer, 1977), como aquella que va llevando al agente a desplazar los antiguos esquemas, arrastrado por la misma fuerza-energía vital que se genera en la experiencia, y con este movimiento, a elaborar nuevas formas de "pensar" en lo que le está sucediendo y lo que está sucediendo, experiencia dialéctica. De este proceso, pudimos entender que "van emergiendo" nuevas respuestas a las necesidades que se suceden en la situación. Así termina de configurarse, según pudimos concluir, una nueva forma de enfrentar el conflicto/crisis recuperando, además, viejos elementos conceptuales que sirven en muchos casos, como ya explicitamos, como obstáculos antagónicos o visiones a trascender. A estas prácticas las denominamos, prácticas de diástoles de escape, porque en su expansión dejaron huellas de experiencia en los y las entrevistadas que de ella participaron. Son prácticas que se escaparon de las prácticas de imágenes estereotipadas educativas que reproducen el sistema hegemónico, con impacto real para la transformación, tanto en los y las docentes, como en los y las estudiantes que las recuerdan porque las vivieron como participantes.

Las pensamos como prácticas de "pequeñas" decolonizaciones, sobre todo para los y las enseñantes, que abren un espacio para habitar las instituciones educativas de otro modo, y que además, si bien no poseen las características de las pedagogías decoloniales, su existencia provoca discontinuidades que afectan a los agentes, incorporando otros relatos en el dispositivo escolar, según pudimos advertir.

- Para nuestro asombro, observamos que ciertas políticas públicas, decisiones en la macroestructura, son portadoras de procesos descolonizadores, según quedó visibilizado a través de los relatos de experiencias educativas. El hecho de que el ingreso dejara de ser restricto y selectivo (2005) en la Universidad Nacional del Comahue y el IFDC, hizo que jóvenes provenientes de muchos sectores socioculturales ingresaran a la formación de formadores. Esto nos llevó a comprender cómo, junto a la apertura de muchos docentes hacia otros horizontes epistemológicos no reproductivos, esto permite que circule en las aulas, e incluso en las prácticas de la enseñanza y residencia, otros modos de pensar y conceptualizar la realidad y otros contenidos pertenecientes a epistemologías invisibilizadas.

\section{C'onculsiói}

A partir del camino que anduvimos a lo largo de todo este proceso de tesis, y sobre la base de las conclusiones y aportes que acabamos de compartir, sostengo que el hecho de volver sobre nuestras propias huellas de experiencias como educadoras/ educadores investigadores en la universidad y en institutos de formación docente,

15 "No buscamos otra cosa, nada menos, que liberar al hombre de color de sí mismo" (Frantz Fanon, citado por Walsh, 2013, p. 160). 
nos habilita un habitar coherente y vital con nuestro compromiso social, y que en esta reflexividad se abre un espacio de posibilidad para nosotras/os y otro/as, retomando lo elaborado en dialéctica con el aquí y ahora situado, para encontrar nuevos rumbos de acción e investigación en este lugar de vacancia desde donde partimos y al que regresamos con el aporte de comprensiones y pistas.

Como aporte reflexivo, rescato, que si bien observamos que hay dispositivos pedagógicos que arman escenas estereotipadas, según los relatos de experiencias, estos tienen, a modo de hipótesis, menos impacto en nuestros días en este lugar y como función en la reproducción hegemónica que en tiempo atrás, por lo que la categoría de dispositivos pedagógicos, ${ }^{16}$ a nuestro entender, si bien brinda analizadores que son de utilidad, a la hora de indagar en las colonizaciones, esta categoría, no es suficiente.

Percibimos que, en todo caso y en relación a la construcción de subjetividades políticas, donde mayor atención habría que poner actualmente, en dirección a los procesos de colonización, es en la estructura organizativa educativa que impacta en forma preobjetiva, repetitiva y performativa; generando aprendizajes adicionales de ser, estar, hacer y conocer; a partir de su formato fraccionado, de mucho contenido en poco tiempo, de horarios discutibles para nuestra región y con normativas de acreditación que acotan la posibilidad de inclusión de ritmos diferentes para la aprehensión pedagógica; trayendo como consecuencia, aprendizajes superficiales ${ }^{17} \mathrm{y}$ acostumbramientos a ritmos preconcebidos (alienaciones), sostenidos desde lógicas monótonas y de monocultura, contrarias a las requeridas para impulsar y estimular la creatividad, ${ }^{18}$ el relato diverso de corporeidades y la legitimación de otros saberes y saberes otros, y con esto la transformación socioeducativa.

Por último y según lo visibiliza la empiria, entendemos que la mirada no enjuiciadora del docente es fundamental en el rescate de la alteridad y de la valorización del saber del otro, y que además, con su compromiso vital y sincero con la enseñanza, este posibilita escenarios que empoderan a los y las estudiantes, porque los y las vitalizan. Estos aspectos son pilares fundantes en la construcción de escenarios pedagógicos decoloniales sin que necesariamente estos estén ligados a didácticas ancestrales ni a teorías de retaguarda como sostienen otros teóricos; es decir, que para nosotras, luego de esta investigación, estos escenarios también se constituyen como pedagogías decoloniales.

\section{ReFrericulls}

Alliaud, A. (2004, enero 15). La experiencia escolar de los maestros inexpertos: biografías, trayectorias y práctica profesional. Revista Iberoamericana de Educación, 34(1), 1-13. Recuperado de https://rieoei.org/RIE/article/view/2888/3821

${ }^{16}$ Sostenida como marco de disciplinamiento.

${ }^{17}$ Por lo cual el, las docentes nóveles posee elementos conceptuales/epistemológicos débiles para proponer nuevos escenarios pedagógicos. Y de hecho ninguno de los escenarios de enseñanza se apoyó en un relato en este sentido, a pesar de que la capacitación continua se plantea desde allí.

${ }^{18}$ Capacidad fundamental, desde nuestros análisis, para provocar transformaciones duraderas y profundas; es decir, de colonizaciones de mentalidades. 
Apple, M. (1987). Educación y poder. Barcelona, España: Paidós.

Bennet, S.N. y Jordan, J. (1975, febrero). A typology of teaching styles in primary schools. Revista Educacional Psychology, 45(1), 20-28. Recuperado de https://onlinelibrary.wiley.com/doi/ abs/10.1111/j.2044-8279.1975.tb02291.x

Berardi, F. (2007). El sabio, el mercader y el guerrero. Del rechazo al trabajo al surgimiento del cognitariado. Madrid, España: Ediciones Acuarela Libros.

Botero Gómez, P. (2014, marzo). Escuela y trans-formación: pluri-versando desde nuestros aprendizajes colectivos. En I Congreso internacional de educación para pensar la diversidad. Mesa 2: Interculturalidad y subjetividades: Pluralidad, emergencias y diferencias. Manizales, Colombia: Centro Editorial de Universidad de Manizales.

Botero Gómez, P. (2015). Resistencias. Relatos del sentirpensamiento que caminan la palabra. Manizales, Colombia: Centro Editorial de Universidad de Manizales.

Botero Gómez, P., Alvarado Muñoz, M. y Ospina, F. (2008, noviembre 11). Las tramas de la subjetividad política y los desafíos a la formación ciudadana en jóvenes. Revista Argentina de Sociología, 6(11), 19-43. Recuperado de http://www.redalyc.org/pdf/269/26911765003.pdf

Botero Gómez, P., Carmona López, M. y Loiza de la Pana, J. (2007, noviembre 12). Subjetividad y política: una perspectiva performativa. Revista de Ciencias Humana. UTP, 12(37), 137- 154. Recuperado de http://revistas.utp.edu.co/index.php/chumanas/article/view/1145

Bourdieu, P. y Passeron J. C. (1996). La reproducción: elementos para una teoría de la enseñanza. (2da. Ed.). Barcelona, España: Ed. Laia.

Dewey, J. (2008). El arte como experiencia. Ciudad de México, México: Fondo de Cultura Económica.

Duch, L., Lamaniego, M., Capdevida y Solares, B. (2008). Lluís Duch, antropología simbólica y corporeidad cotidiana. Cuadernos de Hermenéutica, (2). Recuperado de http://biblioteca. clacso.edu.ar/Mexico/crim-unam/20100429110200/SolaresDuch.pdf

Dunkin, M. y Biddle, B. (1974). The study of teaching. Nueva York, Estados Unidos: Ed. Holt, Rinehart and Winston.

Edelstein, G. (2011). Formarse y formar en la enseñanza. Buenos Aires, Argentina: Ed. Paidós.

Escobar, A. (2003, octubre, 7). Mundos y conocimientos de otro modo. Revista Tabula Rasa, 1(1), 51-86. Recuperado de http://www.redalyc.org/html/396/39600104/

Escobar, A. (2016, abril). Sentipensar con la Tierra: las luchas territoriales y la dimensión ontológica de las epistemologías del sur. Revista de Antropología Iberoamericana, 11(1), 11- 32. Recuperado de http://www.aibr.org/antropologia/netesp/ numeros/1101/110102.pdf

Fannon, F. (1973). Piel negra, máscaras blancas. Buenos Aires, Argentina: Ed. Abraxas.

Foulcaut, M. (1975). Vigilar y castigar. Buenos Aires, Argentina: Ed. Siglo XXI.

Freire, P. (2005). La educación como práctica de la libertad. México. Ed. Siglo XXI.

Gadamer, H. (1977). Verdad y método. Salamanca, España: Ed. Sígueme.

Giroux, H. (1990). Los profesores como intelectuales. Hacia una pedagogía crítica del aprendizaje. Barcelona, España: Ed. Paidós.

Glaser, B. y Strauss, A. (1967). The discovery of grounded theory: Strategies for qualitative research. New York, United States: Ed. Aldine Publishing company.

Grosfoguel, R. (2006). La descolonización de la economía política y los estudios poscoloniales. Transcoloniedad, pensamiento fronterizo y colonialidad global. Revista Tabula Rasa, (4), 1748. Recuperado de http://www.ceapedi.com.ar/imagenes/biblioteca/libros/114.pdf

Guattari, F. y Rolnick, S. (2006). Micropolitica. Cartografía del deseo. Madrid, España: Ed. Traficantes de sueños.

Hall, S. (2006). Estudios culturales dos paradigmas Revista Colombiana de Sociología, 1(27), 233-254. Recuperado de http://www.revistas.unal.edu.co/index.php/recs/article/ viewFile/7981/8625.

Jackson, P. (1999). Enseñanzas implicitas. Buenos Aires, Argentina: Ed. Amorrortu.

Mandoki, K. (1994). Prosaica. Introducción a la estética de lo cotidiano Madrid, España: Ed. Grijalbo 
Mclaren, P. (1995). La escuela como un performance ritual: hacia una economía política de los simbolos y gestos educativos. Buenos Aires, Argentina: Ed. Siglo XXI.

Mignolo, W. (2003). Historias locales, diseños globales. Colonialidad, conocimiento subalterno y pensamiento fronterizo. Madrid, España: Ed. Akal

Moreira, K.; Gois de Souza, M. (2007). Influência de Boaventura de Sousa Santos em pesquisas em educacao no Brasil. Revista Travesias Pesquisas em educacao, cultura linguagem e arte 1 (1), pp. 413-123. Río de Janeiro. Brasil

Moustakas, C.E. (1994). Phenomenological Research Methods. California: Sage

Porta, L. y Silva, M. (2003, abril). La investigación cualitativa: el análisis de contenido en la investigación educativa Revista electrónica de investigación educativa. Recuperado de: http://anthropostudio.com/wp-content/uploads/2015/04/PORTA-Luis-y-SILVA-Miriam2003.-La-investigaci\%C3\%B3n-cualitativa.-El-An\%C3\%A1lisis-de-Contenido-en-lainvestigaci\% $\% 3 \%$ B3n-educativa.pdf

Prada Alcoreza, R. (2013). Epistemología, Pluralismo y decolonialización. La Paz. Bolivia: Ed. UMSA

Quijano, A. (1988) Modernidad, identidad y utopía en América Latina Lima, Perú: Sociedad Política ediciones.

Souza Santos, B. (2010). Descolonizar el saber, Reinventar el poder. Recuperado de: http:// www.boaventuradesousasantos.pt/media/Descolonizar\%20el\%20saber_final\%20-\%20 $\mathrm{C} \% \mathrm{C} 3 \%$ B3pia.pdf

Souza Santos, B. y Meneses, M.P (2014). Epistemologías del Sur. Buenos Aires, Argentina: Ed. Akal

Scott, J. (1999, julio) Experiencia. Revista Hiparquia, 10, (1) pp. 59-83. Argentina. Buenos Aires: Asociación argentina de Mujeres en Filosofía

Stodosky, H. (1991). La importancia del contenido en la enseñanza: actividades en las clases de matemática y ciencias sociales. Ciudad de México, México: Ed. Paidós

Taylor, S. J. y Bogdan, R. (1987). Introducción a los métodos cualitativos de investigación. La búsqueda de significados. Barcelona, España: Ed. Paidós

Vega Cantor, R. (2012, octubre, 16). La expropiación del tiempo en el capitalismo actual Revista Herramienta debate y critica marxista 5 (51). Recuperado de: http://www.herramienta.com. ar/revista-herramienta-n-51/la-expropiacion-del-tiempo-en-el-capitalismo-actual

Walsh, C. (2013) Pedagogías decoloniales prácticas insurgentes de resistir, re existir y revivir. Quito, Ecuador: Ediciones Abya Yala.

Walsh, C. (2014). Lo pedagógico y lo colonial: entretejiendo caminos. Lima, Perú: Ed. Querétaro.

Zibechi, R. (2015). Descolonizar el pensamiento crítico y las prácticas emancipadoras. Bogotá, Colombia: Ed. Desde Abajo. 